\title{
A miniaturized solid-contact potentiometric multisensor platform for determination of ionic profiles in human saliva
}

\author{
Marcin Urbanowicz ${ }^{1}$ (D) Dorota G. Pijanowska ${ }^{1} \cdot$ Artur Jasiński $^{2} \cdot$ Marcin Ekman $^{3} \cdot$ Maria K. Bocheńska $^{2}$
}

Received: 2 September 2019 /Revised: 11 October 2019 / Accepted: 14 October 2019/Published online: 11 November 2019

(C) The Author(s) 2019

\begin{abstract}
This paper describes a miniaturized multisensor platform (MP-ISES) consisting of electrodes: a reference one (RE) and ionselective electrodes (ISEs) for monitoring $\mathrm{Na}^{+}, \mathrm{K}^{+}, \mathrm{Ca}^{2+}, \mathrm{Mg}^{2+}, \mathrm{Cl}^{-}$, and $\mathrm{SCN}^{-}$ions and $\mathrm{pH}$ in human saliva. Gold electrode surface was modified by deposition of two layers: electrosynthesized PEDOT:PSS forming an intermediate layer, and ionselective membrane. The developed ISEs were characterized by a wide linear range and sensitivity consistent with the Nernst model. The entire MP-ISEs are characterized by satisfactory metrological parameters demonstrating their applicability in biomedical research, in particular in measurements concerning determination of ionic profiles of saliva. Saliva samples of 18 volunteers aged from 20 to 26 participating in a month experiment had been daily collected and investigated using the MPISEs assigned individually to each person. Personalized profiles of ions (ionograms) in saliva, such as $\mathrm{Na}^{+}, \mathrm{K}^{+}, \mathrm{Ca}^{2+}, \mathrm{Mg}^{2+}, \mathrm{Cl}^{-}$, $\mathrm{SCN}^{-}$, and $\mathrm{H}^{+}$, were obtained.
\end{abstract}

Keywords Potentiometric multisensor platform $\cdot$ Personalized ion profiles (ionograms) in human saliva $\cdot$ Solid-contact ion-selective electrodes $\cdot$ Simultaneous determination of ion concentration

\section{Introduction}

For many years, direct potentiometry and ion-selective electrodes have been useful tools for determining ion concentration in human body fluids [1-3], since then they have still been used in medical analyses for determination of $\mathrm{Na}^{+}, \mathrm{K}^{+}$, $\mathrm{Ca}^{2+}$, and $\mathrm{Cl}^{-}$ions [4-6]. The classical ion-selective electrodes (ISEs), due to their design, e.g., large dimensions, are not compatible with modern clinical applications, which aims at reducing the sample volume. For this reason, for decades, vast part of research was focused on the elimination of the

Marcin Urbanowicz

murbanowicz@ibib.waw.pl

$1 \quad$ Nalecz Institute of Biocybernetics and Biomedical Engineering Polish Academy of Sciences, Ks. Trojdena 4, 02-109 Warsaw, Poland

2 Department of Chemistry and Technology of Functional Materials, Chemical Faculty, Gdańsk University of Technology, Narutowicza 11/12, 80-233 Gdańsk, Poland

3 Department of Surgical Oncology, Medical University of Gdańsk, Smoluchowskiego 17, 80-214 Gdańsk, Poland classic redox system (e.g., $\mathrm{Ag} / \mathrm{AgCl}$ with liquid internal electrolyte) by designing electrodes in solid-contact technology [7-24]. The use of solid-contact technology enabled design of the ISEs in planar technology, their miniaturization, and unquestionably widening range of implementation of ISEs, including clinical and biological analyses of small volume samples [25-28]. The solid-contact electrode (SCE) consists of an intermediate layer, for example, an electroconductive polymer deposited on the electrode and covered by an ionselective membrane $[29,30]$. The electrode may be platinum-, gold-, or carbon-based materials, e.g., glassy carbon.

However, eliminating the classic redox system and replacing it with the intermediate layer cause some problems. From a practical point of view, these difficulties concern the insufficient long-term stability of the potential and poor reproducibility of duplicated electrodes, which makes them difficult to exchange e.g. inside analyzers. So far, these problems have been solved for glass and crystalline electrodes, where the slope of characteristics is typically stable, regardless of whether it is a classic design or SCE type. However, changes of SCE-ISE standard potential are unpredictable causing parallel shifts of the calibration curve, which in turn reduces the accuracy of the measurements if the calibration is not frequently enough. Therefore, frequent calibration is performed to 
increase the accuracy of analysis. The SSE-type electrodes are very attractive when the possibility of miniaturization is considered. Nevertheless, their small size usually increases the electrical resistance of the electrode, which consequently may decrease signal-to-noise ratio and instability of the potential. The same effect may be caused by incorporating a conductive polymer, which changes properties under influence of light, and it may affect the redox systems, e.g., in the presence of oxygen or due to the change of $\mathrm{pH}[29,31-41]$. In addition, in many works confirmed, the capability of ion-selective membranes based on polyvinyl chloride (PVC) to sorb water, which affects steady-state potential, and in consequence the stability of sensors, e.g., for solid-contact PVC-membranebased ISEs, the stabilization time is long, ranging from 3 to

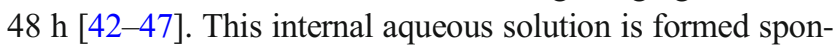
taneously, and its composition depends on the ambient conditions and electrolyte diffusion level through the membrane. As a result, the stability of SCE-ISE deteriorates in particular drift of the potential occurs $[10,43,48]$. Reasonably short response time of SCE-ISEs proves their usability for potentiometric measurements in various applications, such as measurements of concentration of many inorganic ions [10,49,50], ionic surfactants [51], and polyions [52]. Additionally, possibility of miniaturization allows placing ISEs in the needle of the syringe [53] in a way that the measurements can be performed even within the living cells [54]. Noteworthy, it is also possible to replace an electroconductive substrate, such as metal or carbon, with a special plastic PEDOT-PSS Baytron P [55]. Traditional glass-capillary microelectrodes are characterized by a very short lifetime (1 day) [53] in comparison with the solid-contact electrodes.

Maintaining the physiological concentration of ions in body fluids is considered to be one of the key factors of homeostasis [56]. Therefore, monitoring of ion concentration changes in human blood is successfully performed as a basic analysis in medical diagnostics [57]. It is known that the ionic composition of saliva may reflect the health state of the person being examined [58-62]. Due to the correlation of ion concentration with the general health status, the potentiometric measurements can be applied to the assessment of ionic profiles in saliva [62]. Therefore, personalized ion profiles of saliva may deliver new information on condition of patient/ person being examined.

This paper presents the results of the research carried out using the miniature multisensor platform of own construction composed of solid-contact ion-selective electrodes. This work is a continuation of study on the use of miniature ISEs in biomedical research [63]. Our previous article focused on examining some factors influencing ISE response, including lifetime parameters, and also showed the algorithm that allows designing ionic composition of solutions for calibration of MP-ISEs. The purpose of this work demonstrates applicability of the developed MP-ISES, in particular as a useful analytical tool for simultaneous determination of ions in saliva. The MPISES enabled the study of changes in $\mathrm{Na}^{+}, \mathrm{K}^{+}, \mathrm{Ca}^{2+}, \mathrm{Mg}^{2+}$, $\mathrm{Cl}^{-}, \mathrm{SCN}^{-}$, and $\mathrm{H}^{+}$ion concentrations in human saliva. The results in the form of personalized ionograms as well as their analysis are presented.

\section{Experimental}

\section{Chemicals}

The components for electrode membranes, i.e., poly(vinyl chloride) (PVC of high molecular weight), bis(2ethylhexyl)sebacate (DOS) $\geq 97 \%$, o-nitrophenyl octyl ether (o-NPOE) $\geq 99 \%$, chloroparaffin $60 \%$ chlorine basis, and potassium tetrakis $(p$-chlorophenyl)borate $(\mathrm{KTpClPB}) \geq 97 \%$; tridodecylmethylammonium chloride (TDMACl); ionophores selected for the studies, i.e., p-tert-butylcalix[4]arene-tetraacetic acid tetraethyl ester (sodium ionophore $\mathrm{X}$ ), valinomycin (potassium ionophore I), $N, N$-dicyclohexyl- $N^{\prime}, N^{\prime}$-dioctyldecyl-3oxapentane-diamide (calcium ionophore IV), $N, N^{\prime \prime}$ octamethylene-bis $\left(N^{\prime}\right.$-heptyl- $N^{\prime}$-methylmalonamide) (magnesium ionophore III), and tridodecylamine (hydrogen ionophore I), were purchased from Sigma-Aldrich. Tetrakis-(4-triphenylphosphonium-butoxy)-p-tert-butylcalix [4]arene tetrathiocyanate (thiocyanate ionophore) was synthesized at the Faculty of Chemistry, Department of Chemistry and Technology of Functional Materials, Gdańsk University of Technology $[64,65]$. Solvent, i.e., tetrahydrofuran anhydrous $\geq 99 \%$; and conducting polymer components, i.e., 3,4ethylenedioxythiophene (EDOT) and poly(4-styrenesulfonic acid) sodium salt (NaPSS), were purchased from SigmaAldrich. Other chemicals such as inorganic salts, i.e., $\mathrm{NaCl} \geq$ $99.9 \%, \mathrm{KCl} \geq 99.5 \%, \mathrm{CaCl}_{2} \cdot 6 \mathrm{H}_{2} \mathrm{O} \geq 99 \%, \mathrm{MgCl}_{2} \cdot 6 \mathrm{H}_{2} \mathrm{O} \geq$ $99.5 \%, \mathrm{KSCN} \geq 99.5 \%, \mathrm{CH}_{3} \mathrm{COONa} \geq 99.5 \%, \mathrm{CH}_{3} \mathrm{COOLi} \cdot$ $2 \mathrm{H}_{2} \mathrm{O} \geq 99 \%$, KOH, methanol, pH buffer $(5.00 \pm 0.05,7.00 \pm$ $0.05,9.00 \pm 0.05)$, and nitric acid, were obtained from Avantor Performance Materials, Poland S.A. Poly(vinyl acetate) (PVA) and 2,2-dimethoxy-2-phenylacetophenone (DMPA) were from Sigma-Aldrich. Freshly deionized water for aqueous salt solutions was obtained by reverse osmosis (RO) Hydro-Lab-PL station $(\leq 0.1 \mu \mathrm{s} / \mathrm{cm})$.

\section{Preparation of multisensor platforms}

Two potentiometric multisensor platforms (MP-ISEs) selective to two groups of ions were developed. The two MP-ISEs were selective to $\mathrm{Na}^{+}, \mathrm{K}^{+}, \mathrm{Ca}^{2+}$, and $\mathrm{Mg}^{2+}$ and to $\mathrm{Cl}^{-}, \mathrm{SCN}$, and $\mathrm{H}^{+}$ ions, respectively. Each of the MP-ISEs had a 3-mm diameter and consisted of ISEs (Figs. 1 and 2). As a basic electrode material, a $500-\mu \mathrm{m}$-diameter gold wire $(\mathrm{Au} \geq 99.99 \%)$ was used. The gold surfaces were polished with sandpapers of various grain sizes used in the following order: $600,2000,2400$, 
Fig. 1 Scheme of the multisensor platform and solid-contact RE

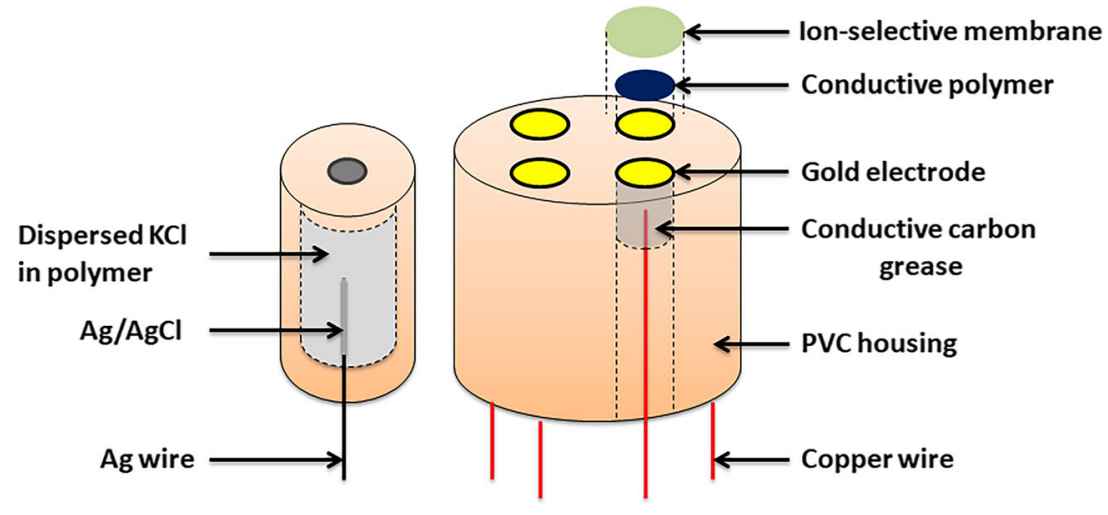

and 4000 and then with $\mathrm{Al}_{2} \mathrm{O}_{3}$ abrasive powder of a grain size of $0.3 \mu \mathrm{m}$ distributed on a wet mesh paper. Then, the surface of electrodes was chemically cleaned by immersing in the following solutions: $1 \mathrm{~mol} \mathrm{dm}^{-3} \mathrm{KOH}$ in methanol, deionized water, $10 \% \mathrm{HNO}_{3}$ and again in deionized water [66]. Before deposition of ion-selective membranes (ISMs), except for electrodes intended to be used for $\mathrm{SCN}^{-}$and $\mathrm{Cl}^{-}$ion detection, the electrosynthesis of PEDOT:PSS layer on the top of $\mathrm{Au}$ wire surfaces was performed by galvanostatic polymerization. The electrochemical cell for the PEDOT:PSS deposition system consisted of the Au wires with polished and cleaned surfaces connected as a working electrode, an auxiliary electrode (glassy carbon rod), and a single junction reference electrode. All the electrodes were immersed in an aqueous solution of the monomer $\left(0.015 \mathrm{~mol} \mathrm{dm}^{-3}\right.$ EDOT) and supporting electrolyte $\left(0.1 \mathrm{~mol} \mathrm{dm}^{-3} \mathrm{NaPSS}\right)$. The PEDOT:PSS was deposited by applying a current density of $0.2 \mathrm{~mA} \mathrm{~cm}$ to the working electrode for $714 \mathrm{~s}[67,68]$. After rinsing with deionized water and drying, the liquid membranes were deposited on the top of the PEDOT:PSS intermediate layer. For this purpose, approximately $0.3 \mu \mathrm{L}$ of the membrane cocktail was applied onto each electrode and allowed to evaporation of the solvent for $24 \mathrm{~h}$. Compositions of ion-selective membrane (ISM) cocktails, expressed in wt.\%, were as follows: Na-ISM: 1.28 sodium
Fig. 2 Construction of the miniature multisensor platform used in the studies: a miniature solid-contact reference electrode; b module of four gold electrodes without ISMs

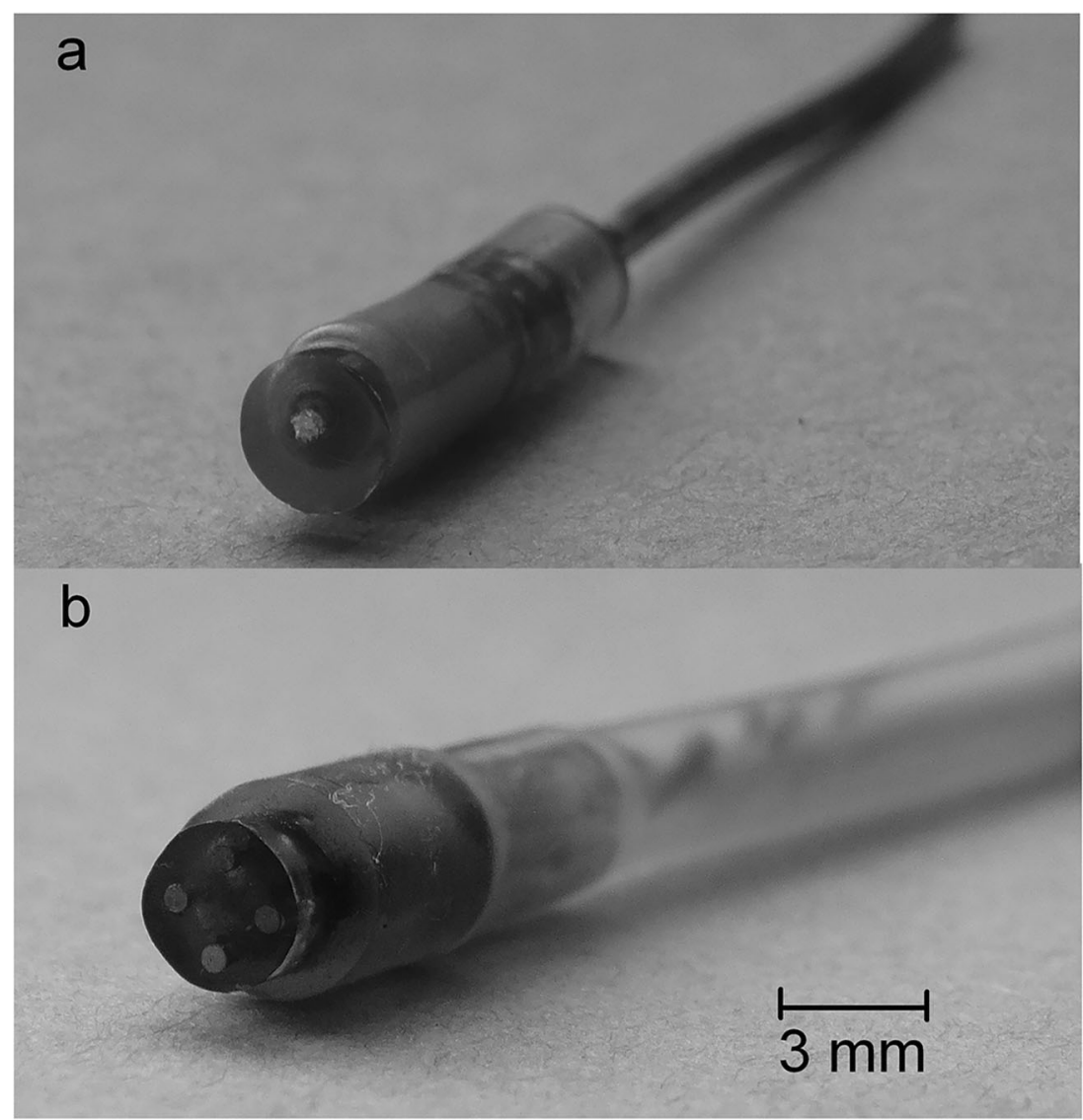


ionophore X, 0.22 KTpCIPB, 65.62o-NPOE, 32.88 PVC; KISM: 1.16 valinomycin, $0.56 \mathrm{KTpClPB}, 65.24 \mathrm{DOS}, 33.04$ PVC; Ca-ISM: 1.33 ETH 5234, $0.46 \mathrm{KTpCIPB,} 64.50$ oNPOE, 33.71 PVC; Mg-ISM: 1.31 ETH 4030, 0.64 KTpCIPB, 65.35 chloroparaffin, 32.70 PVC; Cl-ISM: 7.63 TDMACl, 66.49 o-NPOE, 25.87 PVC; SCN-ISM: 2.22 thiocyanate ionophore, 64.83 chloroparaffin, 32.95 PVC; H-ISM: 1.15 tridodecylamine, 0.58 KTpCIPB, 65.32 DOS, 32.94 PVC.

As for all potentiometric measurements, for MP-ISEs, an integrated and miniature solid-contact reference electrode (RE) is required [69]. For many years, attempts have been made to refine or propose new concepts of RE [67, 70, 71].

In our experiments, the RE was made by dispersion of $\mathrm{KCl}$ crystals within the UV curable polymer [72-75]. At first, the $\mathrm{Ag} / \mathrm{AgCl}$ wire was prepared by electrochemical formation of a silver chloride layer. For this purpose, the pure Ag wire was immersed in a $0.1 \mathrm{~mol} \mathrm{dm}^{-3} \mathrm{HCl}$ and then connected against platinum electrode to a power supply with a fixed voltage and current of $1.5 \mathrm{~V}$ and $40 \mathrm{~mA}$, respectively. Next, vinyl acetate was mixed with milled and dried $\mathrm{KCl}$ in ratio of 1:1 wt.:wt. and then 1 wt.\% of photoinitiator 2,2-dimethoxy-2phenylacetophenone (DMPA) was added. The resulting mixture was stirred, and then, the $\mathrm{Ag} / \mathrm{AgCl}$ wire was inserted and irradiated with UV light at a wavelength of $365 \mathrm{~nm}$.

As a housing for the electrodes, a polyvinyl chloride (PVC) tube was used. The electrical ISE-leads were made of copper wires. In order to ensure a stable electrical connection, the MG Chemicals 8481-2 conductive carbon grease was used. As insulation of electric wires, plastic infusion tubes were utilized.

\section{Measurements in biological samples-saliva's sampling protocol}

The body fluid in the oral cavity is a mixture of saliva produced by salivary glands, gingival fluid, and serum. The saliva maintains oral homeostasis and oral health. Its primary role is to help in the formation of swallowed food and pre-digesting of some substances by enzymes, for example, $\alpha$-amylase. The main components of saliva are as follows: water, enzymes, proteins, and inorganic ions. The composition of saliva depends on the type of salivary glands in which it is secreted. In the human body, three main pairs can be distinguished: parotid, sublingual, and submandibular, which produce $95 \%$ of the volume of saliva which corresponds to $1-1.5 \mathrm{~L}$ per day. The remaining $5 \%$ is produced by the tongue glands and other oral glands. An undoubted advantage of saliva as an analytical sample is relatively easy availability. Nevertheless, due to the complex composition of the sample and the widespread presence of microorganisms in the oral cavity, the collection, processing, and storage of saliva samples are associated with many problems. The saliva collection procedure presented below was based on Lahti et al.'s work [76].
The volume of 2-mL unstimulated saliva samples were collected from 18 healthy volunteers by sterile 10 -mL-volume syringes (Polfa Lublin S.A., Poland) directly from oral cavity every day at 11 am for a course of 1 month. Single collection of a small volume of saliva minimized the risk of stimulating the salivary glands. For 30-min time interval before sampling, volunteers did not eat nor drink. Additionally, in order to limit the mixing of saliva with other fluids, e.g., from the nostrils, the volunteers made the collection of saliva samples by placing the syringe in the mouth so that the tip of the syringe was close to the submandibular gland. The sampling process lasted about 1 min during which the volunteers did not swallow saliva, did not move the tongue, and did not make any unnecessary movements that could stimulate the production of saliva. After sampling at least $2 \mathrm{~mL}$ of the saliva, the tip of the syringe was blinded with a sterile rubber stopper and immediately transferred for centrifugation at $6000 \mathrm{rpm}$ for $6 \mathrm{~min}$ in order to eliminate sediments. Subsequently, the saliva samples were measured by the miniaturized MP-ISE system to determine $\mathrm{Na}^{+}, \mathrm{K}^{+}, \mathrm{Ca}^{2+}, \mathrm{Mg}^{2+}, \mathrm{Cl}^{-}$, and $\mathrm{SCN}^{-}$ions and $\mathrm{pH}$. The measurement was carried out in a glass cell with a rubber cover in which the MP-ISEs were placed. The use of blinding allowed limiting sample contact with air and minimizing the risk of $\mathrm{pH}$ changes. The volume of the test sample was $500 \mu \mathrm{L}$.

\section{Characteristics of the study group}

The research was carried out in a group of volunteers who have signed informed consent to participate in the study. Collection, processing, and analysis using the saliva samples were carried out under the medical supervision of the Department of Oncologic Surgery of Medical University of Gdańsk. Due to the signed agreement of all volunteers, medical supervision, and the lack of body shells violation, the bioethical committee permission was not required, in accordance with Polish law. A total of 18 healthy volunteers, including 11 women and 7 men, aged 20-25 participated in this study. Before sampling the saliva, the volunteers responded to the questionnaire. The volunteers received a questionnaire and randomly chosen part of the code containing the ID, which was marked in the questionnaire and the tube before collecting a saliva sample. In addition, 8 out of 11 women reported no problems with the regularity of the menstrual cycle.

\section{Results}

\section{Parameters of multisensor platforms}

Analytical evaluation of the multisensor platforms (MP-ISEs) included the determination of parameters such as linear range, sensitivity (slope of characteristic), and cross-selectivity 
Table 1 The ISE sensitivity and linear range obtained for measurements with MP-ISE versus liquid junction and solid-contact RE ( $n=9$ repeating for each electrode)

\begin{tabular}{llll} 
ISE & $S_{\text {Orion }}(\mathrm{mV} / \mathrm{dec})$ & $S_{\text {Solid }}(\mathrm{mV} / \mathrm{dec})$ & $\begin{array}{l}\text { Linear range for ISE versus } \\
\mathrm{RE}_{\text {Solid }} \text { in }-\log \left[a / \mathrm{mol} \mathrm{dm}^{-3}\right]\end{array}$ \\
\hline $\mathrm{Na}^{+}$ & $56 \pm 1$ & $56 \pm 1$ & $1-7$ \\
$\mathrm{~K}^{+}$ & $58 \pm 1$ & $58 \pm 1$ & $1-5$ \\
$\mathrm{Ca}^{2+}$ & $28 \pm 1$ & $29 \pm 1$ & $1-8$ \\
$\mathrm{Mg}^{2+}$ & $30 \pm 1$ & $30 \pm 1$ & $1-6$ \\
$\mathrm{Cl}^{-}$ & $-53 \pm 2$ & $-54 \pm 2$ & $1-6$ \\
$\mathrm{SCN}^{-}$ & $-52 \pm 2$ & $-53 \pm 2$ & $1-6$ \\
$\mathrm{pH}$ & $62 \pm 1$ & $61 \pm 1$ & $5-11$ \\
\hline
\end{tabular}

coefficients for interfering ions present in human saliva. The parameters were determined for each ISE with the membrane prepared from cocktails of compositions described in "Preparation of multisensor platforms." Since the RE in the MP-ISEs is of own construction, then, the performance of ISE was compared with results obtained for measurements versus standard commercial RE (Table 1). The selectivity coefficients were calculated according to both separate solution and fixed interference methods (SSM and FIM) and compared with the values shown in the IUPAC technical report [77] and other literature data. Na-ISE obtained more favorable selectivity coefficient $\left(\log K_{\mathrm{Na} / \mathrm{K}}=-2.9\right)$ than that declared by Cadogan [29] $\left(\log K_{\mathrm{Na} / \mathrm{K}}=-2.7\right)$. K-ISE obtained $\log K_{\mathrm{K} / \mathrm{Na}}=-4.0$ while for analogous membrane composition in [77], it obtained $\log K_{\mathrm{K} / \mathrm{Na}}=-3.7$. Ca-ISE obtained $\log K_{\mathrm{Ca} / \mathrm{Mg}}=-4.0$ and was slightly worse than that declared in [78]. For Mg-ISE and Cl-ISE, selectivity coefficient did not differ significantly from those reported in the literature. However, for the SCNISE, the following values of selectivity coefficients were obtained: $\log K_{\mathrm{SCN} / \mathrm{Cl}}=-3.8, \log K_{\mathrm{SCN} / \mathrm{NO} 3}=-1.9, \log K_{\mathrm{SCN} /}$
$\mathrm{HCO}_{3}=-3.0, \log K_{\mathrm{SCN} / \mathrm{H} 2 \mathrm{PO} 4}=-4.2, \log K_{\mathrm{SCN} / \mathrm{SO} 4}=-2.6$. Other values of selectivity coefficients are presented in Fig. 3. To estimate the activity coefficients, the Phreeqc Interactive 3.4.0 software was used. An algorithm of this software includes the Debye-Hückel equation and Pitzer model.

Drift coefficient of the sensor potential during calibration did not exceed $170 \mu \mathrm{V} \mathrm{h}^{-1}$ for cation-selective sensors and $200 \mu \mathrm{V} \mathrm{h}^{-1}$ for anion-selective sensors, while during the measurement of saliva samples, $315 \mu \mathrm{V} \mathrm{h}^{-1}$ and $430 \mu \mathrm{V} \mathrm{h}^{-1}$ for cation- and anion-selective sensors, respectively. Detailed data can be found in Table 2. Long-term stability corresponded with our previous research described in Urbanowicz et al.'s work [63].

The ready-to-use MP-ISEs were stabilized in the conditioning solution of the following compositions: $\mathrm{Na}^{+}, \mathrm{K}^{+}, \mathrm{Ca}^{2+}$, $\mathrm{Mg}^{2+}, \mathrm{SCN}^{-}-1 \mathrm{mmol} \mathrm{dm}^{-3}$ for each ion and $5 \mathrm{mmol} \mathrm{dm}^{-3}$ for $\mathrm{Cl}^{-}$. Electromotive force $(E M F)$ was measured versus both an Orion ROSS Ultra 800500U D/J RE and solid-contact RE of own construction (Fig. 4 and Table 1). The stability of the solid-contact RE has been examined and previously described in Jasinski et al.'s work [68]. The solid-contact RE drift of the potential measured against the classic RE for $14 \mathrm{~h}$ was $5 \mu \mathrm{V}$. The MSP (multisolution protocol) used for investigation of the stability of the electrode response in various types of aqueous solutions, indicated that the electrode is stable in a solution of $0.01 \mathrm{~mol} \mathrm{dm}^{-3} \mathrm{HCl}(11 \mathrm{mV}$ deviation from the initial value $)$ and $3 \mathrm{~mol} \mathrm{dm}^{-3} \mathrm{KCl}$ solution $(10 \mathrm{mV}$ deviation from the initial value). Additionally, positive offset with the liquid junction reference of ca. $+100 \mathrm{mV}$ was obtained. These suggest that the electrode fabrication and design work very well.

The mean saliva ionic strength was modeled by using the Visual Minteq software. Therefore, to increase the accuracy of the measurements, the composition of conditioning and calibration solutions (R1 and R2) were matched to the modeled ionic strength $(I)$ of saliva samples, i.e., $I_{\mathrm{R} 1} \approx I_{\mathrm{R} 2} \approx I_{\text {cond }}$ as
Fig. 3 The MP-ISE selectivity coefficients determined by SSM

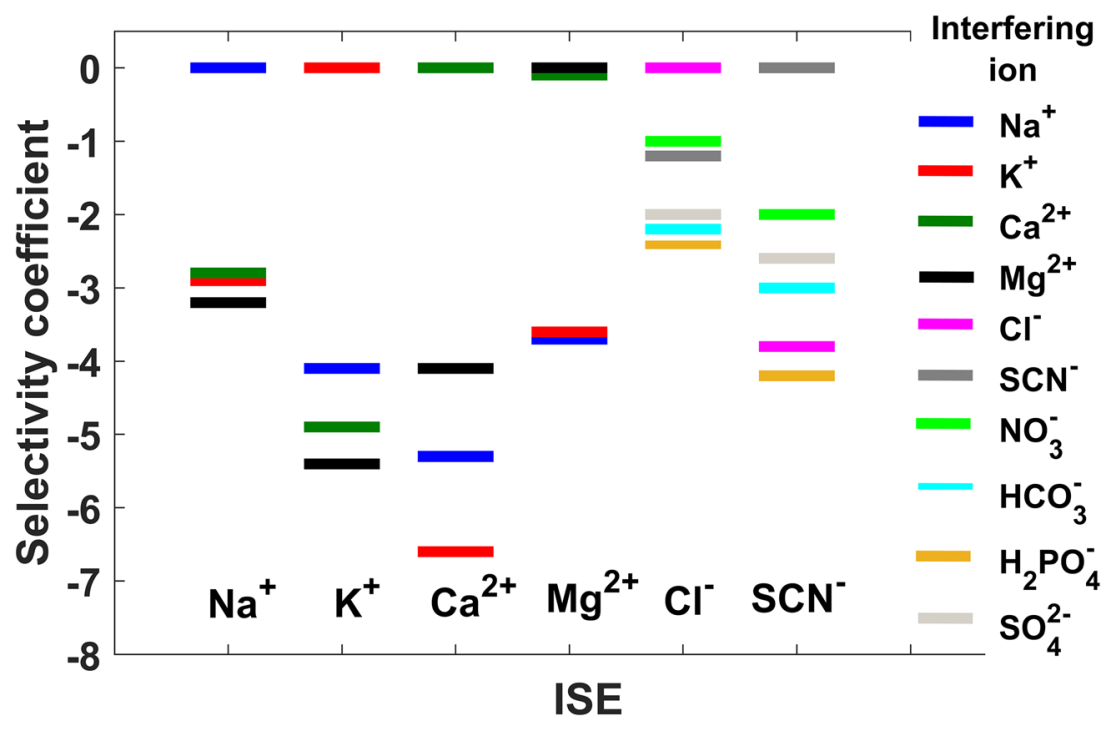


Table 2 Stability of the sensor signals during (A) calibration and (B) measurements in saliva $(n=378$ measurements in saliva and calibration)

\begin{tabular}{llll}
\hline ISE & $S_{\text {Solid }}\left(\mathrm{mV} \mathrm{dec}^{-1}\right)$ & $\begin{array}{l}\text { Drift coeff. A } \\
\left(\mu \mathrm{V} \mathrm{h}^{-1}\right)\end{array}$ & $\begin{array}{l}\text { Drift coeff. B } \\
\left(\mu \mathrm{V} \mathrm{h}{ }^{-1}\right)\end{array}$ \\
\hline $\mathrm{Na}^{+}$ & $56 \pm 2$ & $123 \pm 32$ & $187 \pm 41$ \\
$\mathrm{~K}^{+}$ & $55 \pm 3$ & $94 \pm 27$ & $139 \pm 38$ \\
$\mathrm{Ca}^{2+}$ & $25 \pm 1$ & $111 \pm 52$ & $221 \pm 57$ \\
$\mathrm{Mg}^{2+}$ & $25 \pm 2$ & $170 \pm 60$ & $315 \pm 24$ \\
$\mathrm{Cl}^{-}$ & $-54 \pm 3$ & $261 \pm 46$ & $430 \pm 62$ \\
$\mathrm{SCN}^{-}$ & $-54 \pm 3$ & $202 \pm 37$ & $384 \pm 43$ \\
$\mathrm{pH}$ & $58 \pm 1$ & $88 \pm 25$ & $262 \pm 55$ \\
\hline
\end{tabular}

shown in Table 3. The compositions of calibration solutions $\mathrm{R} 1$ and R2 were designed based on literature data concerning the ionic composition of saliva. For the sake of proper measurements in saliva with the use of the MP-ISEs, the ionic strength of conditioning solution used for stabilization of electrodes was constant and close to the ionic strength of the calibration solutions.

As mentioned above, prior to measurements in saliva, the electrodes were stabilized in the conditioning solution and then calibrated using solutions R1 and R2 of the composition shown in Table 3. The compositions of the solutions were as follows: $\mathrm{R} 110 \mathrm{mmol} / \mathrm{dm}^{3} \mathrm{CH}_{3} \mathrm{COONa}, 10 \mathrm{mmol} \mathrm{dm}{ }^{-3} \mathrm{KCl}$, $5 \mathrm{mmol} \mathrm{dm}{ }^{-3} \mathrm{KSCN}, 0.5 \mathrm{mmol} \mathrm{dm}{ }^{-3} \mathrm{CaCl}_{2} \cdot 6 \mathrm{H}_{2} \mathrm{O}$, $0.1 \mathrm{mmol} \mathrm{dm}^{-3} \mathrm{MgCl}_{2} \cdot 6 \mathrm{H}_{2} \mathrm{O}, 4 \mathrm{mmol} \mathrm{dm}{ }^{-3} \mathrm{CH}_{3} \mathrm{COOLi}$; and $\mathrm{R} 21 \mathrm{mmol} \mathrm{dm}{ }^{-3} \mathrm{CH}_{3} \mathrm{COONa}, 20.5 \mathrm{mmol} \mathrm{dm}^{-3} \mathrm{KCl}$, $0.5 \mathrm{mmol} \mathrm{dm}{ }^{-3} \mathrm{KSCN}, 2 \mathrm{mmol} \mathrm{dm}{ }^{-3} \mathrm{CaCl}_{2} \cdot 6 \mathrm{H}_{2} \mathrm{O}$, $1 \mathrm{mmol} \mathrm{dm}{ }^{-3} \mathrm{MgCl}_{2} \cdot 6 \mathrm{H}_{2} \mathrm{O}$. The methodology for the design of calibration and conditioning solutions was presented in the paper of Urbanowicz et al. [79].

\section{Saliva tests}

The study group consisting of 18 volunteers (23-25 years old, 11 women and $7 \mathrm{men}$ ) was qualified to the experiment. The volunteers received sampling kits and collected samples themselves according to the previously agreed methodology. Each participant was obliged to fill in the questionnaire.

Based on the collected data, mean ion concentrations (Table 4) were determined. The values of ion concentration correspond to those reported in literature [80]. The highest concentration was observed for $\mathrm{Cl}^{-}$and $\mathrm{K}^{+}$, and the lowest for $\mathrm{Mg}^{2+}, \mathrm{Ca}^{2+}$, and $\mathrm{SCN}^{-}$. The largest spread around the mean values of concentration was observed for $\mathrm{Na}^{+}$. High fluctuation of sodium concentration may be caused by the influence of various types of stimuli, which has been previously described at Urbanowicz et al.'s work [75]. In the case of $\mathrm{K}^{+}$, the spread of mean concentration values is significantly
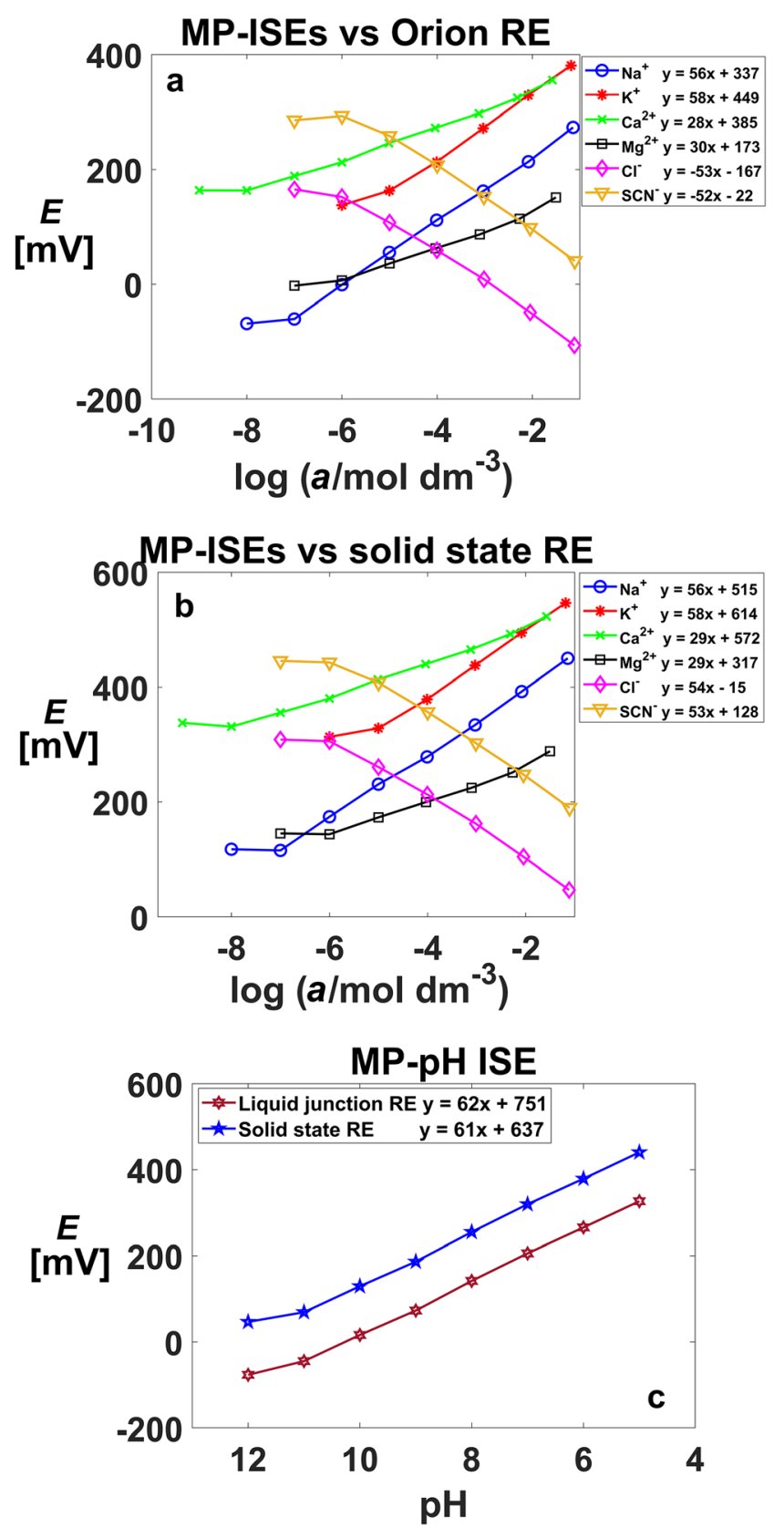

Fig. 4 The determined calibration curves for MP-ISEs. a Calibration curves for $\mathrm{Na}^{+}, \mathrm{K}^{+}, \mathrm{Ca}^{2+}$, and $\mathrm{Mg}^{2+}$ and for $\mathrm{Cl}^{-}$and $\mathrm{SCN}-$ ISE versus a liquid junction RE (Orion). b Calibration curves for $\mathrm{Na}^{+}, \mathrm{K}^{+}, \mathrm{Ca}^{2+}$, and $\mathrm{Mg}^{2+}$ and for $\mathrm{Cl}^{-}$and $\mathrm{SCN}$ ISE versus solid-contact RE. $\mathbf{c}$ Calibration curves for $\mathrm{H}^{+}$ISE versus liquid junction (Orion) and solid-contact RE. Equations of calibration curves have been shown in legends

smaller than for $\mathrm{Na}^{+}$. Minor standard deviations are also observed for $\mathrm{pH}$ and $\mathrm{Mg}^{2+}$.

For all volunteers, the monthly concentration profiles of $\mathrm{Na}^{+}, \mathrm{K}^{+}, \mathrm{Ca}^{2+}, \mathrm{Mg}^{2+}, \mathrm{Cl}^{-}, \mathrm{SCN}^{-}$, and $\mathrm{H}^{+}$ions (called ionograms) were determined. Examples of ionograms are shown in Fig. 5.

Monthly ionograms for $\mathrm{Na}^{+}, \mathrm{K}^{+}, \mathrm{Cl}^{-}$, and $\mathrm{pH}$ show a difference between the genders. For men, fluctuations of ion 
Table 3 Ionic composition of calibration R1 and R2, and conditioning/ storing solutions for MP-ISEs in saliva measurement

\begin{tabular}{llll}
\hline Ions & $\begin{array}{l}\mathrm{R} 1 \\
(\mathrm{mmol} \mathrm{dm}\end{array}$ & $\begin{array}{l}\mathrm{R} 2 \\
(\mathrm{mmol} \mathrm{dm}\end{array}$ & $\begin{array}{l}\text { Conditioning/storing } \\
\text { sol. }\left(\mathrm{mmol} \mathrm{dm}^{-3}\right)\end{array}$ \\
\hline $\mathrm{Na}^{+}$ & 10 & 1 & 5 \\
$\mathrm{~K}^{+}$ & 15 & 20.5 & 17 \\
$\mathrm{Ca}^{2+}$ & 0.5 & 2 & 1 \\
$\mathrm{Mg}^{2+}$ & 0.1 & 1 & 0.3 \\
$\mathrm{SCN}^{-}$ & 5 & 0.5 & 1 \\
$\mathrm{Cl}^{-}$ & 11.2 & 26.5 & 17.6 \\
$\mathrm{Li}^{+}$ & 4 & 0 & 5 \\
$\mathrm{CH}^{+} \mathrm{COO}^{-}$ & 14 & 1 & 10 \\
Ionic strength, $I$ & 0.303 & 0.303 & 0.298 \\
$\left(\mathrm{mmol} / \mathrm{dm}^{3}\right)$ & & & \\
\hline
\end{tabular}

concentration are more dynamic than for women. As it was mentioned earlier, higher dynamics of changes in $\mathrm{Na}^{+}$concentration for men might be caused primarily by their higher physical activity. For $\mathrm{K}^{+}$, in the majority of cases, the concentration changes were minor and could be caused by meals rich in potassium. An interesting observation has been made for $\mathrm{Ca}^{2+}$ concentration in women saliva. In the saliva samples of 4 women with a regular menstrual cycle, for whom a single increase of $\mathrm{Ca}^{2+}$ concentration was observed. In the case of other women and men, none similar changes were observed. The obtained data suggest that there might be a relationship between the $\mathrm{Ca}^{2+}$ concentration in the women saliva and the menstrual cycle. However, the above hypothesis would require detailed research in this area, especially clinical trials. In the case of $\mathrm{Mg}^{2+}$, no characteristic concentration changes were observed.

The parameter with minor fluctuations during the month was $\mathrm{pH}$. Slight changes in $\mathrm{pH}$ for individual volunteers indicate that the saliva sampling procedure was carried out correctly. Longterm contact with air, contamination with external microorganisms, and overgrowth of physiological bacterial flora in the sample could have a significant impact on the sample $\mathrm{pH}$, and thus could affect the ionic form of determined ions: $\mathrm{Ca}^{2+}$ and $\mathrm{Mg}^{2+}$. For $\mathrm{Cl}^{-}$, there was a large variability of concentration during the month for individual volunteers, which makes it difficult for interpretation. Monthly monitoring of $\mathrm{SCN}^{-}$

Table 4 Mean, standard deviation (SD), and variance $(\sigma)$ for determined ions in saliva (number of collected samples, $n=378$ )

\begin{tabular}{llllllll}
\hline Parameter & $\mathrm{Na}^{+}$ & $\mathrm{K}^{+}$ & $\mathrm{Ca}^{2+}$ & $\mathrm{Mg}^{2+}$ & $\mathrm{pH}$ & $\mathrm{Cl}^{-}$ & $\mathrm{SCN}^{-}$ \\
\hline Mean $\left(\mathrm{mmol} \mathrm{dm}^{-3}\right)$ & 5.64 & 16.85 & 0.95 & 0.33 & 6.96 & 23.26 & 0.82 \\
$\mathrm{SD}\left(\mathrm{mmol} \mathrm{dm}^{-3}\right)$ & $5.41^{*}$ & 1.97 & 0.15 & 0.11 & 0.18 & 2.60 & 0.27 \\
$\sigma$ & 29.24 & 3.89 & 0.02 & 0.01 & 0.03 & 6.78 & 0.07 \\
\hline
\end{tabular}

*SD is the result of very large differences between subjects, which may result from physical activity, diet, and stressful situations [74]
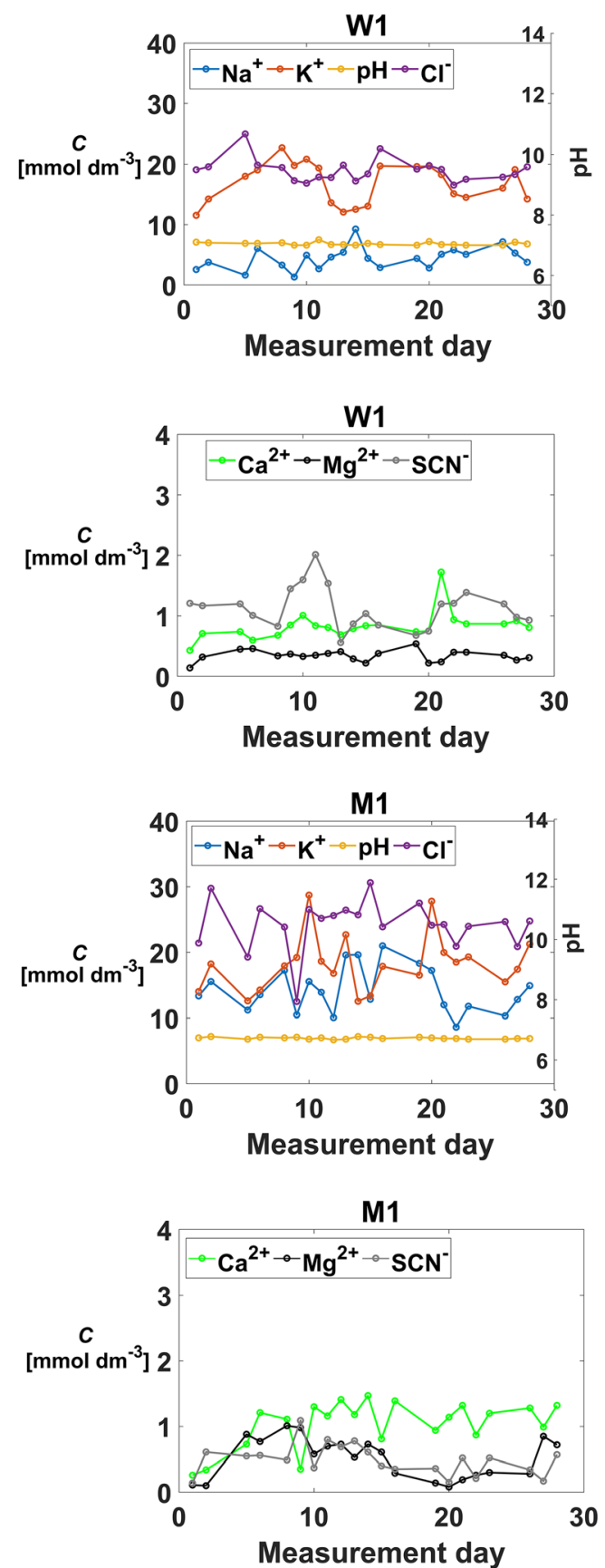

Fig. 5 Exemplary 28-day saliva ion profiles for woman and man

concentration has shown that its level can change dramatically. Between 9 and 11 measurement day for 10 volunteers, a sharp increase in $\mathrm{SCN}^{-}$concentration was observed in saliva. None of these volunteers declared smoking. Possible reasons for a sudden increase in the $\mathrm{SCN}^{-}$concentration in saliva could be the effect of passive smoking or prolonged staying in a place with increased smoke, for example, a walk on a crowded street.

In summary, in our research, new solid-contact potentiometric multisensor platforms with $\mathrm{Na}^{+}, \mathrm{K}^{+}, \mathrm{Ca}^{2+}, \mathrm{Mg}^{2+}, \mathrm{Cl}^{-}$, $\mathrm{SCN}^{-}$, and $\mathrm{H}^{+}$ISEs were described. MP-ISEs were successfully applied for the determination of the abovementioned ions 
in human saliva. MP-ISEs' utilization enables quick and simultaneous measurements of ion concentration.

\section{Conclusions}

In this paper, newly developed multisensor platforms (MPISEs) based on solid-contact ion-selective electrodes and miniaturized solid-contact reference electrode were presented. The MP-ISEs exhibited satisfactory parameters such as the sensitivity, selectivity, and linear range. The selectivity coefficients for the tested electrodes were identical or even better than those given in the IUPAC technical report [77]. The multianalyte calibration method for sensors in the MP-ISEs was successfully applied, which enabled simultaneous determination of selected ions in the small samples of complex matrix. The reference electrode without the internal liquid electrolyte was used, which allowed maintaining its size compatible in relation to the MP-ISEs. The developed MP-ISEs based on ion-selective electrodes turn out to be a reliable analytical tool for simultaneous determination of selected ions such as $\mathrm{Na}^{+}, \mathrm{K}^{+}, \mathrm{Ca}^{2+}, \mathrm{Mg}^{2+}, \mathrm{Cl}^{-}$, and $\mathrm{SCN}^{-}$in human saliva presented in form of personalized ionograms for the group of 18 volunteers. The presented MP-ISEs might be potentially useful analytical tool for biomedical applications that can provide valuable and long-term data on health status.

Funding information The authors received partial financial support (DS 030893) from Gdańsk University of Technology, Gdańsk 80-233, PL.

Open Access This article is distributed under the terms of the Creative Commons Attribution 4.0 International License (http:// creativecommons.org/licenses/by/4.0/), which permits unrestricted use, distribution, and reproduction in any medium, provided you give appropriate credit to the original author(s) and the source, provide a link to the Creative Commons license, and indicate if changes were made.

\section{References}

1. Arnold MA, Meyerhoff ME (1984) Ion-selective electrodes. Anal Chem 56:20-48

2. Oesch U, Ammann D, Simon W (1986) Ion-selective membrane electrodes for clinical use. Clin Chem 32(8):1448-1459

3. Lewenstam A, Maj-Zurawska M, Hulanicki A (1991) Application of ion-selective electrodes in clinical analysis. Electroanalysis 3: 727-734

4. Bobacka J, Ivaska A, Lewenstam A (2008) Potentiometric Ion Sensors. Chem Rev 108:329-351

5. Bakker E (2016) Electroanalysis with Membrane Electrodes and Liquid-Liquid Interfaces. Anal Chem 88(1):395-413

6. Platzer V, Hebraud B, Causse E (2017) Alternative process for quantifying $\mathrm{Na}+$ and $\mathrm{K}+$ electrolytes in plasma with high paraprotein concentration using an automated analyzer. Clin Biochem 50:544-545
7. Oyama N, Hirokawa T, Yamaguchi S, Ushizawa N, Shimomura T (1987) Hydrogen ion selective microelectrode prepared by modifying an electrode with polymers. Anal Chem 59:258-262

8. Oyama N, Ohsaka T, Yoshimura F, Mizunuma M, Yamaguchi S, Ushizawa N, Shimomura T (1988) Ion-Selective Electrodes Based on Bilayer Film Coating. J Macromol Sci Chem 25:1463-1473

9. Garnier F (1989) Functionalized Conducting Polymers - Towards Intelligent Materials. Agnew Chem Int Ed 28:513-517

10. Lewenstam A, Bobacka J, Ivaska A (1994) Mechanism of ionic and redox sensitivity of p-type conducting polymers: Part 1 . Theory. J Electroanal Chem 23:23-31

11. Bobacka JT, Lindfors T, McCarrick M, Ivaska A, Lewenstam A (1995) Single-piece all-solid-state ion-selective electrode. Anal Chem 67:3819-3823

12. Bobacka J, Ivaska A, Lewenstam A (2003) Potentiometric Ion Sensors Based on Conducting Polymers. Electroanalysis 15:366374

13. Grimes CA, Dickey EC, Pishko MV, Marcus PRA (2006) Encyclopedia of sensors. Publishers, American Scientific

14. Lai C-Z, Joyer MM, Fierke MA (2009) Subnanomolar Detection Limit Application of Ion-Selective Electrodes with ThreeDimensionally Ordered Macroporous (3DOM) Carbon Solid Contacts. J Solid State Electrochem 13(1):123-128

15. Yin Pan D, Qin W (2012) A solid-contact Pb2+-selective polymeric membrane electrode with Nafion-doped poly(pyrrole) as ion-toelectron transducer. J Solid State Electrochem 16:499-504

16. Ansari R, Delavar AF, Mohammad-khan A (2012) Solid-state ion selective electrode based on polypyrrole conducting polymer nanofilm as a new potentiometric sensor for $\mathrm{Zn} 2+$ ion. J Solid State Electrochem 16:3315-3322

17. Lee E, Jeong E, Jeon S (2012) A potentiometric sensor of silver ions based on the Schiff base of diphenol. J Solid State Electrochem 16: 2591-2596

18. Xu K, Xu G, Lv J, Cui J, Wu Y (2013) Pt nanoparticles modified Au nanowire array for amperometric and potentiometric detection of glucose. J Solid State Electrochem 17:2381-2389

19. Lewenstam A (2014) Routines and Challenges in Clinical Application of Electrochemical Ion-Sensors. Electroanalysis 26: 1171-1181

20. Nooredeen NM, Abd El-Ghaffar MA, Darwish WM, Elshereafy E (2015) Graphene oxide with covalently attached zinc monoaminophthalocyanine coated graphite electrode as a potentiometric platform for citrate sensing in pharmaceutical preparations. J Solid State Electrochem 19:2141-2154

21. Stanic Z, Stepanović J (2016) Potentiometric determination of ascorbic acid in water-acetonitrile solution using pyrite and chalcopyrite electrodes. J Solid State Electrochem 20:2879-2893

22. Nooredeen M, Margar H (2018) Highly sensitive and selective solid-contact calcium sensor based on Schiff base of benzil with 3 -aminosalycilic acid covalently attached to polyacrylic acid amide for health care. J Solid State Electrochem 22:181-192

23. Rezk MR, Fayed AS, Marzouk HM, Abbas SS (2018) Potentiometric ion-selective electrodes for determination of cyclopentolate hydrochloride and phenylephrine hydrochloride in their challenging ophthalmic formulation. J Solid State Electrochem 22:3351-3361

24. Shvedene NV, Abashev MN, Arakelyan SA, Otkidach KN, Tomilova LG, Pletnev IV (2019) Highly selective solid-state sensor for iodide based on the combined use of platinum (IV) phthalocyanine and solidified pyridinium ionic liquid. J Solid State Electrochem 23:543-552

25. Bobacka J, Gao ZQ, Ivaska A, Lewenstam A (1994) Mechanism of ionic and redox sensitivity of p-type conducting polymers: Part 2 . Experimental study of polypyrrole. J Electroanal Chem 368:33-41 
26. Hulstein JJ, van't Sant P (2011) Sweat analysis using indirect ionselective electrode on the routine chemistry analyser meets UK guidelines. Ann Clin Biochem 48(Pt 4):374-376

27. Guzinski M, Jarvis JM, D’Orazio P, Izadyar A, Pendley BD, Lindner E (2017) PEDOT(PSS) as Solid Contact for IonSelective Electrodes: The Influence of the PEDOT(PSS) Film Thickness on the Equilibration Times. Anal Chem 89(6):35083516

28. Nakata S, Arie T, Akita S, Takei S (2017) Wearable, Flexible, and Multifunctional Healthcare Device with an ISFET Chemical Sensor for Simultaneous Sweat $\mathrm{pH}$ and Skin Temperature Monitoring. ACS Sens 2(3):443-448

29. Cadogan A, Gao ZQ, Lewenstam A, Ivaska A, Diamond D (1992) All-solid-state sodium-selective electrode based on a calixarene ionophore in a poly(vinyl chloride) membrane with a polypyrrole solid contact. Anal Chem 64:2496-2501

30. Vazquez M, Bobacka J, Ivaska A, Lewenstam A (2002) Influence of oxygen and carbon dioxide on the electrochemical stability of poly(3,4-ethylenedioxythiophene) used as ion-to-electron transducer in allsolid-state ion-selective electrodes. Sensors Actuators B 82: 7-13

31. Pei QB, Qian RY (1992) Electrode potentials of electronically conducting polymer polypyrrole. Electrochim Acta 37:1075-1081

32. Michalska A, Maksymiuk K, Hulanicki A (1995) On the nature of the potentiometric response of polypyrrole in acidic solutions. J Electroanal Chem 392:63-68

33. Li Z, Li X, Petrovic S, Harrison JD (1996) Dual-Sorption Model of Water Uptake in Poly(vinyl chloride)-Based Ion-Selective Membranes: Experimental Water Concentration and Transport Parameters. Anal Chem 68:1717-1725

34. Wise DL (1998) Electrical and optical polymer systems CRC Press

35. Michalska A, Maksymiuk K (1999) The specific influence of hydrogen ions on poly(pyrrole) potentiometry. Electrochim Acta 44: 2125-2129

36. Maksymiuk K, Bobacka J, Ivaska A, Lewenstam A (2000) Coupled Redox and $\mathrm{pH}$ Potentiometric Responses of Electrodes Coated with Polypyrrole. Anal Lett 33:1339-1360

37. Michalska A, Nadrzycka U, Maksymiuk K (2001) The Modelled and Observed Transition from Redox to Ionic Potentiometric Sensitivity of Poly(pyrrole). Electrochim Acta 46:4113-4123

38. Dumańska J, Maksymiuk K (2001) Studies on Spontaneous Charging / Discharging Processes of Polypyrrole in Aqueous Electrolyte Solutions. Electroanalysis 13:567-573

39. Michalska A, Dumańska J, Maksymiuk K (2003) Lowering the Detection Limit of Ion-Selective Plastic Membrane Electrodes with Conducting Polymer Solid Contact and Conducting Polymer Potentiometric Sensors. Anal Chem 75:4964-4974

40. Michalska A, Maksymiuk K (2004) Conducting Polymer Membranes for Low Acivity Potentiometric Ion Sensing. Talanta 63(1):109-117

41. Michalska A (2005) Improvement of Analytical Characteristic of Calcium Selective Electrode with Conducting Polymer Contact. The Role of Conducting Polymer Spontaneous Charge Transfer Processes and Their Galvanostatic Compensation. Electroanalysis 17:400-407

42. Li Z, Li X, Rothmaier M, Harrison JD (1996) Comparison of Numerical Modeling of Water Uptake in Poly(vinyl chloride)Based Ion-Selective Membranes with Experiment. Anal Chem 68:1726-1734

43. Fibbioli M, Bandyopadhyay K, Liu SG, Echegoyen L, Enger O, Diederich F, Bühlmann P, Pretsch E (2000) Redox-active self-assembled monolayers as novel solid contacts for ion-selective electrodes. Chem Commun 5:339-340

44. De Marco R, Veder JP, Clarke G, Nalson A, Prince K, Pretsch E, Bakker E (2008) Elimination of undesirable water layers in solid contact polymeric ion-selective electrodes. Phys Chem Chem Phys 10(1):73-76

45. Lindfors T, Sundfors F, Hofler L, Gyurcsanyi RE (2009) FTIR-ATR study of water uptake and diffusion through ion-selective membranes based on plasticized poly(vinyl chloride). Electroanalysis 21:1914-1922

46. Górski Ł, Matusevich A, Pietrzak M, Wang L, Meyerhoff ME, Malinowska E (2009) Influence of Inner Transducer Properties on EMF Response and Stability of Solid-Contact Anion Selective Membrane Electrodes Based on Metalloporphyrin Ionophores. J Solid State Electrochem 13:157-164

47. Sundfors F, Hofler L, Gyurcsanyi RE, Lindfors T (2011) Influence of Poly(3-octylthiophene) on the Water Transport Through Methacrylic-Acrylic Based Polymer Membranes. Electroanalysis 23:1769-1772

48. Lindfors T, Aarnio H, Ivaska A (2007) Potassium-Selective Electrodes with Stable and Geometrically Well-Defined Internal Solid Contact Based on Nanoparticles of Polyaniline and Plasticized Poly(vinyl chloride). Anal Chem 79(22):8571-8577

49. Michalska A, Ivaska A, Lewenstam A (1997) Modeling Potentiometric Sensitivity of Conducting Polymers. Anal Chem 69:4060-4065

50. Kovacs A, Csoka B, Nagy G, Ivaska A (2001) All-solid-state surfactant sensing electrode using conductive polymer as internal electric contact. Anal Chim Acta 437:67-76

51. Fordyce K, Shvarev A (2008) Solid-Contact Electrochemical Polyion Sensors for Monitoring Peptidase Activities. Anal Chem 80(3):827-833

52. Lamaka SV, Taryba MG, Zheludkevich ML, Ferreira MGS (2009) Novel solid-contact ion-selective microelectrodes for localized potentiometric measurements. Electroanalysis. https://doi.org/10. 1002/elan.200900258

53. Rubinova N, Chumbimuni-Torrez K, Bakker E (2007) Solidcontact potentiometric polymer membrane microelectrodes for the detection of silver ions at the femtomole level. Sensors Actuators B 121:135-141

54. Michalska A, Maksymiuk K (2014) All-plastic, disposable, low detection limit ion-selective electrodes. Anal Chim Acta 523:97105

55. Piro B, Mattana G, Zrig S, Anquetin G, Battaglini N, Capitao D, Maurin A, Reisberg S (2018) Fabrication and use of organic electrochemical transistors for sensing of metabolites in aqueous media. Appl Sci https://doi.org/10.3390/app8060928

56. Lewenstam A in: Comprehensive analytical chemistry, Vol. 49, Electrochemical sensor analysis (Eds: S. Alegret, A. Merkoci), Elsevier, Amsterdam 2007

57. Ammazzini S, Onor M, Pagliano E, Mester Z, Campanella B, Pitzalis E, Bramanti E, D’Ulivo A (2015) Determination of thiocyanate in saliva by headspace gas chromatography-mass spectrometry, following a single-step aqueous derivatization with triethyloxonium tetrafluoroborate. J Chromatogr A 1400:124-130

58. Tanaka Y, Naruishi N, Fukuya H, Sakata J, Saito K, Wakida S (2004) Simultaneous determination of nitrite, nitrate, thiocyanate and uric acid in human saliva by capillary zone electrophoresis and its application to the study of daily variations. J Chromatogr A 1051(1-2):193-197

59. Pajari U, Poikonen K, Larmas M, Lanning M (1989) Salivary immunoglobulines, lysozyme, $\mathrm{pH}$ and microbial counts in children receiving anti-neoplastic therapy. Scand J Dent Res 97(2):171-177

60. Ko W-C, Liu C-L, Lee J-J, Liu T-P, Yang P-S, Hsu Y-C, Cheng S-P (2014) Negative association between serum parathyroid hormone levels and urinary perchlorate, nitrate, and thiocyanate concentrations in U.S. adults: the National Health and Nutrition Examination Survey 2005-2006. PLoS One. https://doi.org/10.1371/journal. pone. 0115245 
61. Kanthale P, Kumar A, Upadhyay N, Lal D, Rathod G, Sharma V (2015) Qualitative test for the detection of extraneous thiocyanate in milk. J Food Sci Technol 52:1698-1704

62. Jackson SL, Cogswell ME, Zhao L, Terry AL, Wang CY, Wright J, Coleman King SM, Bowman B, Chen TC, Merritt R, Loria CM (2018) Association Between Urinary Sodium and Potassium Excretion and Blood Pressure Among Adults in the United States: National Health and Nutrition Examination Survey, 2014. Circulation 137(3):237-246

63. Urbanowicz M, Jasiński A, Bocheńska M, Pijanowska DG (2019) The computational methods in the development of a novel multianalyte calibration technique for potentiometric integrated sensors systems. J Solid State Electrochem 23:2251-2260

64. Pomećko R, Asfari Z, Hubscher-Bruder V, Bocheńska M, ArnaudNeu F (2007) A new phosphonium calix[4]arene for selective anion recognition: synthesis and studies in solution and in ion selective electrodes. Supramol Chem 7:459-466

65. Pomećko R, Asfari Z, Hubscher-Bruder V, Bocheńska M, ArnaudNeu F (2010) Anion recognition by phosphonium calix[n]arenes: synthesis and physico-chemical studies. Supramol Chem 22:275288

66. Guzinski M, Jarvis JM, Pendley BD, Lindner E (2015) Equilibration Time of Solid Contact Ion-Selective Electrodes. Anal Chem 87(13):6654-6659

67. Wagner M, Lisak G, Ivaska A, Bobacka J (2013) Durable PEDOT: PSS films obtained from modified water-based inks for electrochemical sensors. Sensors Actuators B 181:694-701

68. Jasiński A, Urbanowicz M, Guziński M, Bocheńska M (2015) Potentiometric Solid-Contact Multisensor System for Simultaneous Measurement of Several Ions. Electroanalysis 27: 745-751

69. Zuliani C, Matzeu G, Diamond D (2014) A liquid-junction-free reference electrode based on a PEDOT solid-contact and ionogel capping membrane. Talanta 125:58-64

70. Zou X, Chen L, Lai C, Buhlmann P (2015) Ionic Liquid Reference Electrodes With a Well-Controlled Co(II)/Co(III) Redox Buffer as Solid Contact. Electroanalysis 27:602-608
71. Zou X, Buhlmann P (2013) Current Pulse Based Reference Electrodes Without Liquid Junctions. Anal Chem 85:3817-3820

72. Guziński M, Bocheńska M, Berdat D, Wunderli S, "New reference electrode with solid electrolyte", VIII Polish Conference of Analytical Chemistry, Analytics for Society of the 21st Century, Cracow, 4-9 July 2010

73. Guziński M (2013) PhD dissertation. Gdańsk University of Technology, Gdańsk

74. Mausavi Z, Granholm G, Sokalski T, Lewenstam A (2013) An analytical quality solid-state composite reference electrode. Analyst 138:5216-5220

75. Urbanowicz M, Jasiński A, Jasińska M, Drucis K, Ekman M, Szarmach A, Suchodolski R, Pomećko R, Bocheńska M (2017) Simultaneous Determination of $\mathrm{Na}+, \mathrm{K}+, \mathrm{Ca} 2+, \mathrm{Mg} 2+$ and $\mathrm{Cl}-$ in Unstimulated and Stimulated Human Saliva Using All Solid State Multisensor Platform. Electroanalysis 29:2232-2238

76. Lahti M, Vilpo J, Hovinen J (1999) Spectrophotometric Determination of Thiocyanatein Human Saliva. J Chem Educ 76: $1281-1282$

77. Umezawa Y, Buhlmann P, Umezawa K, Tohda K, Amemiya S (2000) Potentiometric Selectivity Coefficients of IonSelective Electrodes. Part I. Inorganic Cations (Technical Report). Pure Appl Chem 72:1851-2082

78. Gehrig P, Rusterholz B, Simon W (1989) Very lipophilic calcium. ion-selective ionophore for chemical sensors of high life-time. Chimia 43:377

79. Urbanowicz M, Pijanowska DG, Jasiński A, Bocheńska M (2018) Multianalyte Calibration Methods for Potentiometric Integrated Sensors System for Determination of Ions Concentration in a Body Fluids. 2018 XV International Scientific Conference on Optoelectronic and Electronic Sensors (COE). https://doi.org/10. 1109/COE.2018.8435148

80. Aps JKM, Martens LC (2005) Review: The physiology of saliva and transfer of drugs into saliva. Forensic Sci Int 150(2-3):119-131

Publisher's note Springer Nature remains neutral with regard to jurisdictional claims in published maps and institutional affiliations. 